\title{
The Performance of $p$-Aminosalicylic Acid As Reducing and Stabilizing Agent in Silver Nanoparticles Synthesis
}

\author{
DIAN SUSANTHY ${ }^{1}$, SRI JUARI SANTOSA ${ }^{1 *}$ and EKO SRI KUNARTI ${ }^{1}$ \\ 'Department of Chemistry, Faculty of Mathematics and Natural Sciences, Universitas Gadjah Mada, \\ Sekip Utara Bulaksumur, Yogyakarta, 55281, Indonesia. \\ ${ }^{*}$ Corresponding author E-mail: sjuari@ugm.ac.id \\ http://dx.doi.org/10.13005/ojc/350106
}

(Received: September 06, 2018; Accepted: January 07, 2019)

\begin{abstract}
In this study, silver nanoparticles (AgNPs) were successfully synthesized using $p$-aminosalicylic acid as a reducing and stabilizing agent simultaneously. The AgNPs were synthesized by mixing silver nitrate solution as a precursor with the $\mathrm{pH}$ adjusted by $p$-aminosalicylic acid solution and heating it in a boiling water bath. The formed AgNPs were analyzed using UV-Vis spectrophotometry to evaluate their SPR absorbance in the wavelength range of $400-500 \mathrm{~nm}$. The optimum reaction time is $10 \mathrm{~min}$ and the optimum $\mathrm{pH}$ is 11 . The AgNPs resulted in the optimum synthesis condition have average size of $32.3 \mathrm{~nm}$, spherical morphology, and face-centered cubic crystal characterized by using PSA, TEM, and XRD, respectively. The formed AgNPs had good stability for more than 2 months. The mechanism of silver ion reduction and AgNPs stabilization by $p$-aminosalicylic acid were also proposed in the paper based on the FTIR analysis result.
\end{abstract}

Keywords: $p$-aminosalicylic acid, Reducing agent, Silver nanoparticles, Stabilizing agent, Surface plasmon resonance(SPR), Particle size analysis (PSA).

\section{INTRODUCTION}

Silver nanoparticles (AgNPs) are very popular nanomaterial. In addition to the abundance of silver in the earth crust, silver nanoparticles also have a broad spectrum of bactericidal activity, surface plasmon resonance absorption, and low cost of manufacturing ${ }^{1}$. For these reasons, AgNPs have been used in many application, such as antimicrobial agent ${ }^{2,3,4}$, part of environmental treatments, such as air, water, and surface disinfection ${ }^{5}$, and as chemical sensors for ammonia ${ }^{6}$, chlorine dioxide ${ }^{7}$, herbicides ${ }^{8}$, copper ions ${ }^{9}$, and lead ${ }^{10}$.
In this study, the "AgNPs were synthesized"by chemical reduction method. Chemical reduction method is preferable because of its convenience factor, relatively low cost, and likely to be produced on a large scale ${ }^{11}$. The reducing agent will reduce the positive silver ion from the precursor solution to become zero charged silver particles which further will become AgNPs. The stabilizing agent was used to form a system, which can protect the AgNPs and prevent aggregation ${ }^{12}$. Many studies have been conducted by using different chemicals as reducing and stabilizing agents ${ }^{13,14,15}$. However, AgNPs synthesis by using only one chemical as

This is an Open Access article licensed under a Creative Commons license: Attribution 4.0 International (CC- BY). Published by Oriental Scientific Publishing Company @ 2018

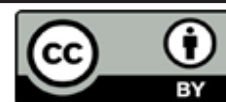


both reducing and stabilizing agent is preferable than using two different chemicals. Some previous study had been conducted by using benzoic acid derivatives with hydroxy phenolic group as reducing and stabilizing agent in the AgNPs synthesis ${ }^{16,17,18}$. However, the use of benzoic acid derivatives with amino and hydroxyl phenolic groups has not been performed yet.

In order to discover the role of each functional group in benzoic acid derivative, $p$-aminosalicylic acid was used in this research as reducing and stabilizing agent in AgNPs synthesis. The amino and hydroxyl phenolic groups were predicted to reduce the $\mathrm{Ag}^{+}$ions to become $\mathrm{Ag}^{0}$, and the carboxylate groups will stabilize the formed AgNPs. This study critically examines the effect of the amino group addition or substitution on the benzoic acid derivatives as both reducing agents of $\mathrm{Ag}^{+}$to $\mathrm{Ag}^{0}$ and as stabilizing agents for the formed AgNPs. Furthermore, a comparison was made with existing research which used other benzoic acid derivative in AgNPs syntheses, such as hydroxybenzoic acid and dihydroxybenzoic acid". The parameter examined includes the particle size, shape, and stability. In addition, the AgNPs formation and stability mechanism by $p$-aminosalicylic acid were also proposed based on the FTIR spectra of synthesized AgNPs.

\section{EXPERIMENTAL}

\section{Materials}

All reagents were used as received without further purification. Silver nitrate Merck \& Co. as precursor of AgNPs, p-aminosalicylic acid (Sigma Aldrich) as reducing and stabilizing agent, nitric acid and sodium hydroxide Merck \& Co. as pH adjuster.

\section{Synthesis of AgNPs}

Silver nitrate solution $\left(0.3 \times 10^{-3} \mathrm{~mol} / \mathrm{L}\right)$ was added to $\mathrm{pH}$-adjusted $p$-aminosalicylic acid $\left(10 \times 10^{-3} \mathrm{~mol} / \mathrm{L}\right)$ in a test tube with volume ratio of $1: 1$ and homogenized. The mixture was then heated in a boiling water bath for several minutes until it turned yellow which indicates that the AgNPs were formed. After the reaction was finished, the mixture was cooled in tap water and transferred to a small bottle for further analysis. For reaction optimization, some reaction parameters were varied, such as $\mathrm{pH}$
(5-13), reaction time $(0.5,10,15,20,25,30 \mathrm{~min})$, and mole ratio of the reactants.

\section{Characterization of AgNPs}

Synthesized AgNPs were characterized using UV-Vis spectrophotometer (Shimadzu UV-Pharma Spec 1700) in order to measure their SPR absorbance. The scanning was performed at 300-800 $\mathrm{nm}$ wavelength range and quartz cuvette with $1 \mathrm{~cm}$ optical path length. The scanning was performed in fast speed with interval of $1 \mathrm{~nm}$.

For TEM analysis (JEOL JEM-1400), the AgNPs colloid was immersed by copper grid. The immersed copper grid was then dried at room temperature. The image was taken by using $120 \mathrm{kV}$ accelerating voltage. The TEM image was further analyzed using image J software in order to observe the particle size and measure the particle size of AgNPs.

AgNPs were also characterized by X-Ray Diffraction (Rigaku) to confirm the crystal form of AgNPs. The XRD spectra was also used to calculate the particle size of the AgNPs by using DebyeScherrer Equation (Equation 1) where $d$ is average particle size $(\mathrm{nm}), \mathrm{K}$ is constant $(0.9), \lambda$ is the wavelength of X-ray (nm), FWHM is the full width at maxima of the peak, and $\theta$ is the Bragg angle $\left({ }^{\circ}\right)^{19}$.

$$
\mathrm{d}=\frac{180 \times \mathrm{K} \times \lambda}{\mathrm{FWHM} \times \pi \times \cos \theta}
$$

Particle Size Analysis (Horiba SZ-100) was also performed for the synthesized AgNPs to measure the particle size of AgNPs and their polydispersity index using dynamic light scattering method. The temperature of the holder is $25^{\circ} \mathrm{C}$ with scattering angle of $9^{\circ}$. Furthermore, the zeta potential measurement was also performed using the same instrument in order to evaluate the AgNPs stability.

The FTIR analysis (Shimadzu FTIR Prestige-21) was also performed in order to predict the reduction mechanism in the AgNPs synthesis. The FTIR analysis was performed for synthesized AgNPs and $p$-aminosalicylic acid. The AgNPs was separated from their solution using centrifuge with speed of $13000 \mathrm{rpm}$. The separated AgNPs were then dried in the oven at temperature of $65^{\circ} \mathrm{C}$. The dried AgNPs were then mixed with $\mathrm{KBr}$ and formed into pellet. The pellet was analyzed in wavelength range of $400-4000 \mathrm{~cm}^{-1}$. 


\section{RESULTS AND DISCUSSION}

\section{The Effect of Acidity in AgNPs Synthesis}

Solution acidity is one important parameter for the synthesis of AgNPs. In this study, the $\mathrm{pH}$ of $p$-aminosalicylic acid was varied from 5 to 13 . The solution could not be more acidic because $p$-aminosalicylic acid could not be dissolved when $\mathrm{pH}$ was lower than 5. It could not be more basic since the silver ions in the silver nitrate solution as precursor would be reduced to solid silver above $\mathrm{pH}$ 13. The formation of AgNPs was indicated by the occurrence of absorbance band in the wavelength range of $400-500 \mathrm{~nm}$. This band was known as SPR absorbance of $\mathrm{AgNPs}^{20}$.

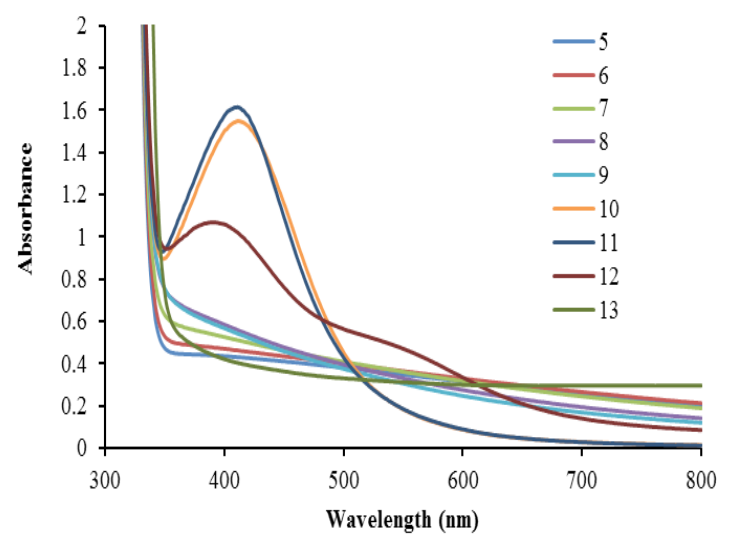

Fig. 1. The spectra of the reaction product between of $0.3 \times 10^{-3} \mathrm{~mol} / \mathrm{L} \mathrm{AgNO}_{3}$ and $50 \times 10^{-3} \mathrm{~mol} / \mathrm{L} p$-aminosalicylic acid at various $\mathrm{pH}$

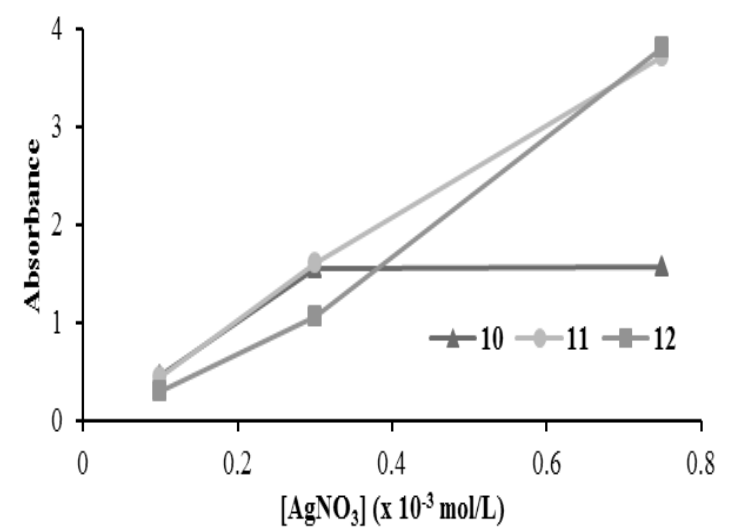

Fig. 2. The SPR Absorbance of AgNPs made from $\mathrm{AgNO}_{3}$ with various concentration $\left(0.1,0.3\right.$, and $\left.0.75 \times 10^{-3} \mathrm{~mol} / \mathrm{L}\right)$ and $50 \times 10^{-3} \mathrm{~mol} / \mathrm{L}$ p-aminosalicylic acid at $\mathrm{pH} 10(\Delta), \mathrm{pH} 11$ (•) and pH $12(\square)$

Based on the spectra in Fig. 1, it can be shown that the reaction can occur at $\mathrm{pH}$ of 10,11 , and 12. AAt pH 10 and 11, the absorption band was at $411 \mathrm{~nm}$ with absorbance of 1.548 and 1.614 $\mathrm{nm}$, respectively. while at $\mathrm{pH} 12$ the absorbance band was at $392 \mathrm{~nm}$ with absorbance of 1.069. In order to make sure the optimum $\mathrm{pH}$ condition, the concentration of silver nitrate solution was varied $\left(0.1,0.3\right.$, and $\left.0.75 \times 10^{-3} \mathrm{~mol} / \mathrm{L}\right)$ for each $\mathrm{pH}$ in order to evaluate the reducing performance and stabilizing performance of $p$-aminosalicylic acid in each $\mathrm{pH}$. The result is shown in Fig. 2. It can be seen that in $\mathrm{pH} 11$, the formed silver nanoparticles in almost every precursor concentration gave the highest absorbance value than other $\mathrm{pH}$. It means that $p$-aminosalicylic acid has the best reducing performance in $\mathrm{pH} 11$.

Furthermore, the result of stability evaluation showed that the silver nanoparticle which synthesized in $\mathrm{pH} 11$ has the better stability than nanoparticles which synthesized in $\mathrm{pH} 12$ because silver nanoparticles which synthesized in $\mathrm{pH} 12$ settled down earlier than silver nanoparticles synthesized in $\mathrm{pH} 11$. Increasing the $\mathrm{pH}$ value of $p$-aminosalicylic acid can improve its reducing performance, but decrease its stabilizing performance on the formed silver nanoparticles and vice versa. Based on these reasons, it can be concluded that $\mathrm{pH} 11$ is the optimum $\mathrm{pH}$ for the silver nanoparticles synthesis with $p$-aminosalicylic acid as reducing and stabilizing agent.

The same optimum $\mathrm{pH}$ was also obtained for several reducing agents, which are the derivatives of the benzoic acid, such as hydroxybenzoic acid ${ }^{16,17}$, dihydroxybenzoi acid $^{18}$, and aminobenzoic acid ${ }^{21}$. The synthesis of AgNPs by using derivatives of benzoic acid is usually conducted under basic conditions. It happens because the benzoic acid group will be deprotonated and the formed negative charge can interact easily with the positive metal ion ${ }^{22}$. under basic conditions due to amino and hydroxyphenolic groups becoming more negatively because their proton atoms are attracted by the base. Therefore, the amino and hydroxyphenolic groups are able to interact more easily with the metal ion.

\section{The Effect of Reaction Time in AgNPs Synthesis}

For the time optimization, the reduction reaction was monitored at the regular time interval using UV-Vis spectrophotometry from 0 to $45 \mathrm{~min}$. The result is shown in Fig. 3 . It can be seen that the 
optimum reaction time is $10 \mathrm{~min}$ since the increase in reaction time above $10 \mathrm{~min}$ did not give a significant increase in the SPR absorbance.

Compared to the previous research with the same $\mathrm{pH}$ condition, reaction temperature, and reactant concentration, AgNPs which was synthesized by $p$-aminosalicylic acid gave higher SPR absorbance in shorter reaction time than AgNPs which synthesized by o-hydroxybenzoic acid16 or p-aminobenzoic acid ${ }^{21}$. On the other hand, compared to silver nanoparticles synthesis with using $\mathrm{o}, \mathrm{p}$-dihydroxibenzoic acid as reducing agent18, the use of $p$-aminosalicylic acid as reducing agent gave resemblant absorbance.

Based on these comparisons, it can be concluded that the amino or hydroxyl group addition can increase the reducing performance of benzoic acid derivative compound because there will be more active sites in the compound. However, compared to hydroxyl group, the amino group substitution did not give any significant difference in its reducing performance.

\section{The Effect of Reactant Mole Ratio in AgNPs Synthesis}

The concentration of each reactant is very important in the formation of AgNPs. In this study, varying the reactant mole ratio was done using $\mathrm{AgNO}_{3}$ with concentration of $0.3 \times 10^{-3} \mathrm{~mol} / \mathrm{L}$ and p-aminosalicylic acid with concentration $0,2,4,6$, 8 , and $10 \times 10^{-3} \mathrm{~mol} / \mathrm{L}$. The spectra of the product from the reaction of various mole ratios of $\mathrm{AgNO}_{3}$ to p-aminosalicylic acid are shown in Figure 4. There were 3 highest absorbance values: 1.40, 1.42, and 1.41 for mole ratio of $1: 20,1: 27$, and $1: 33\left(\mathrm{AgNO}_{3}\right.$ :

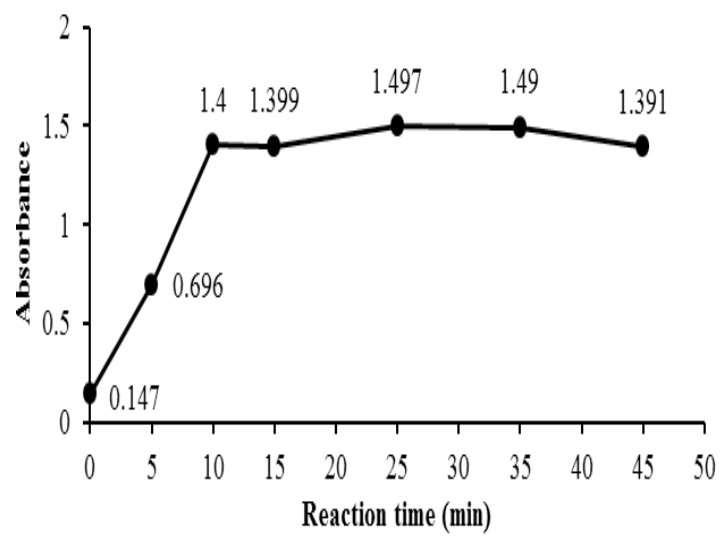

Fig. 3. SPR absorbance of AgNPs made from $0.3 \times 10^{-3}$ $\mathrm{mol} / \mathrm{L} \mathrm{AgNO}_{3}$ and $0.05 \mathrm{~mol} / \mathrm{L} \mathrm{p}$-aminosalicylic acid at $\mathrm{pH} 11$ p-aminosalicylic acid), respectively. It means that $p$-aminosalicylic acid has reached its maximum reducing performance in mole ratio of 1:27 where 1 molecule of $\mathrm{AgNO}_{3}$ was attracted with 27 molecules of $p$-aminosalicylic acid.

The same mole ratio was also used by Susanthy et al., (2017) which used dihydroxybenzoic acid as reducing and stabilizing agent in AgNPs synthesis $^{18}$. But this result was a little bit different with the effective mole ratio of $\mathrm{AgNO}_{3}$ to the $p$-hydroxybenzoic acid which has value $1: 20^{16}$. It can be concluded that the number of active moiety in reducing agent influence the optimum ratio mole of reactant in AgNPs synthesis.

\section{Characterization of AgNPs TEM}

The reducing ability of a reducing agent can be evaluated by the formed particle size. Silver nanoparticles formed through the reduction of $\mathrm{Ag}_{2} \mathrm{O}$ aggregates which then reduced by reducing agent to become $\mathrm{Ag}^{0}$ and finally become silver nanoparticles ${ }^{23}$. Reducing agent with better reducing performance will produce silver nanoparticles with smaller particle size. The TEM image of the optimum AgNPs and its particle size distribution are shown in Fig. 5. It can be seen that AgNPs have a spherical shape. The average particle sizes counted from the TEM image are $14.55 \pm 7.13 \mathrm{~nm}$.

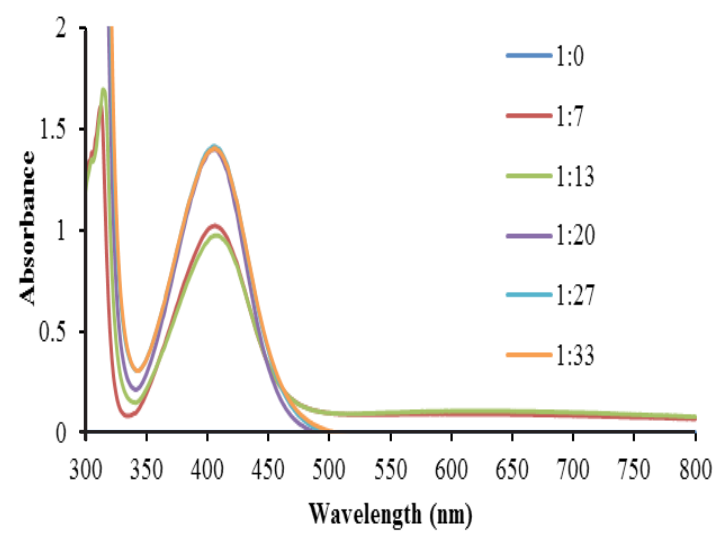

Fig. 4. The SPR Spectra of AgNPs produced from the reaction of various mole ratios of $\mathrm{AgNO}_{3}$ with p-aminosalicylic acid at $\mathrm{pH} 11$

Compared to the previous study, AgNPs synthesized using p-aminosalicylic acid has smaller size compared with AgNPs synthesized by using hydroxybenzoic acid $^{16,17}$ and dihydroxybenzoic $\operatorname{acid}^{18}$. However, AgNPs in this research are still not 
uniform, some particles stick to each other because the reduction process had not finished and kept going on even under room condition. Based on these result in the term of the formed particle size, the addition or substitution of amino groups in benzoic acid derivative compound can increase its reducing performance on silver nanoparticle synthesis.

\section{Particle Size Analyzer}

The synthesized AgNPs was also analyzed by particle size analyzer to obtain the more accurate particle size. The result showed that the AgNPs which synthesized using $p$-aminosalycilic acid had average particle size of $32.3 \mathrm{~nm}$ with PI value of 0.34 . This result was bigger than using TEM because the PSA measure the all particles in the solution, including some bigger silver particle which had not become silver nanoparticles, while TEM measure particular part of the solution. The zeta potential value of the synthesized AgNPs is $-21.3 \mathrm{mV}$. It means that the synthesized AgNPs was capped by negative charge which most likely comes from the deprotonized carboxylate moiety. However, the zeta potential value of AgNPs capped by p-aminosalicylic acid was not high enough give stable nanoparticle because it was smaller than $30 \mathrm{mV}^{24}$.

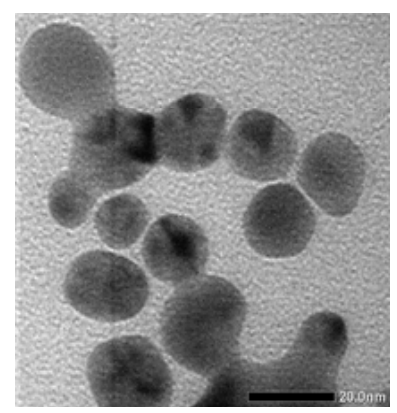

Fig. 5. TEM images of AgNPs synthesized by using $0.3 \times 10^{-3}$ $\mathrm{mol} / \mathrm{L} \mathrm{AgNO}_{3}$ and $10 \times 10^{-3} \mathrm{~mol} / \mathrm{L}$ p-aminosalicylic acid at $\mathrm{pH} 11$ and a reaction time of $10 \mathrm{~min}$

The XRD spectra of the synthesized AgNPs was showed in Fig. 6. Compared to AgNPs which synthesized with chitosan-polyethylene glycol ${ }^{25}$, there were 4 similar peaks, they are peaks in $2 \theta$ of $38.10^{\circ}, 44.34^{\circ}, 64.64^{\circ}$, and $77.38^{\circ}$ which were characteristics to face-centered cubic of AgNPs.

The obtained peaks from XRD spectra also can be used to calculate the particle size of the nanoparticles by using Debye-Scherrer Equation (1) where $\mathrm{d}$ is average particle size $(\mathrm{nm}), \mathrm{K}$ is constant $(0.9), \lambda$ is the wavelength of X-ray $(\mathrm{nm}), \mathrm{FWHM}$ is the full width at maxima of the peak, and $\theta$ is the Bragg angle $\left({ }^{\circ}\right)^{19}$. The average calculated particle size is $22.07 \pm 3.08 \mathrm{~nm}$. This value is higher than particle size which obtained from TEM data but smaller than particle size which obtained from PSA data. However, the particle size comparison with AgNPs synthesized by hydroxybenzoic acid or dihydroxybenzoic acid only can be performed from TEM data, because the authors did not provide the PSA and XRD data.

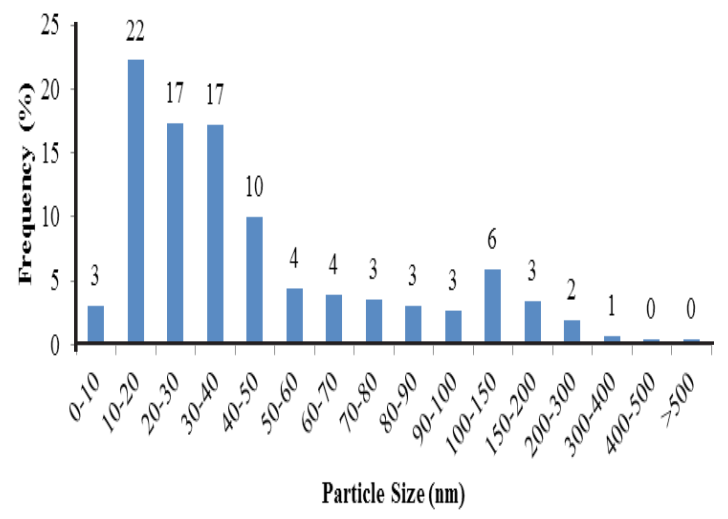

Fig. 6. Particle size distribution of AgNPs synthesized by using $0.3 \times 10^{-3} \mathrm{~mol}^{2} \mathrm{~L} \mathrm{AgNO}_{3}$ and $10 \times 10^{-3} \mathrm{~mol} / \mathrm{L}$ p-aminosalicylic acid at $\mathrm{pH} 11$ and a reaction time of 10 minutes

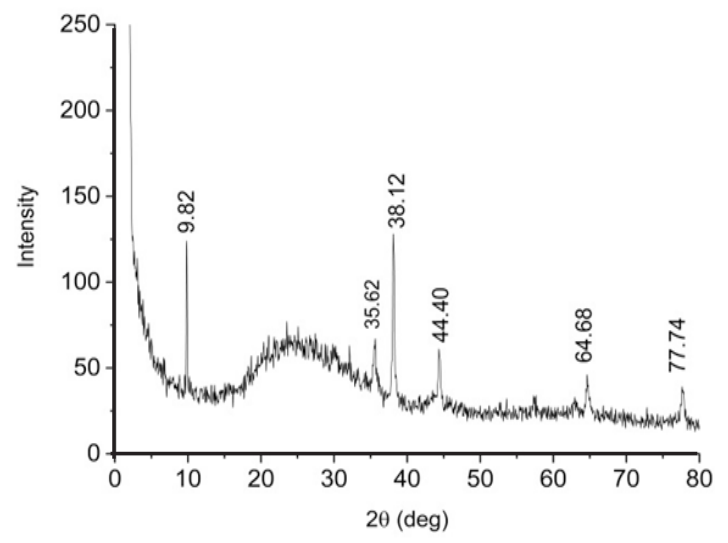

Fig. 7. XRD Spectra of AgNPs synthesized by using $0.3 \times 10^{-3}$ $\mathrm{mol} / \mathrm{L} \mathrm{AgNO}_{3}$ and $10 \times 10^{-3} \mathrm{~mol} / \mathrm{L} \mathrm{p}$-aminosalicylic acid at $\mathrm{pH}$ 11 and a reaction time of 10 minutes

\section{FTIR}

The reduction of $\mathrm{Ag}^{+}$ion to become AgNPs involved the amino and hydroxyl moieties of $p$-aminosalicylic acid. It can be seen from the spectra of $p$-aminosalicylic acid (Fig. 7), the amino moiety 
gave strong absorption in wavenumber of 3495 and $3387 \mathrm{~cm}^{-1}$ which are twin peaks indicating the primary amino moiety. This absorption is disappeared in the AgNPs capped by $p$-aminosalicylic acid spectra and covered by a wide peak of carboxylic acid. The alkene absorption around $3000 \mathrm{~cm}^{-1}$ was decreased which means that the number of double bond between carbon becomes smaller.

\section{The Stability Evaluation of AgNPs}

In order to evaluate the $p$-aminosalicylic acid performance as stabilizing agent, the stability of synthesized AgNPs was evaluated. The AgNPs colloid is stored in a closed bottle at normal laboratory condition. The SPR absorbance of AgNPs was observed in some time interval until 10 weeks. The colloid visually looked similar after 10 weeks of storage and the SPR spectra change can be seen in Fig. 9. After 10 weeks, the wavelength number of SPR was not changed, but the absorbance changes as much as 0.137 or $7 \%$ from the initial absorbance.

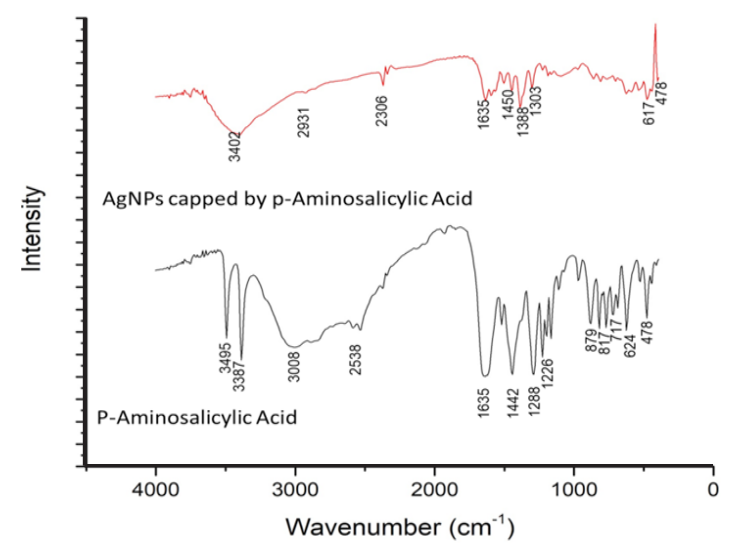

Fig. 8. FTIR Spectra of $p$-minosalicylc acid and AgNPs capped by $p$-aminosalicylic acid

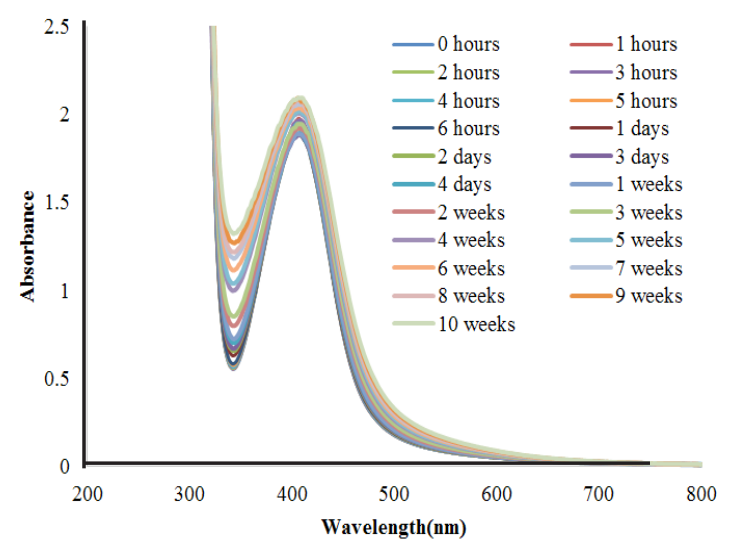

Fig. 9. The SPR Spectra of AgNPs synthesized by using $0.3 \times 10^{-3} \mathrm{~mol} / \mathrm{L} \mathrm{AgNO}_{3}$ and $10 \times 10^{-3} \mathrm{~mol} / \mathrm{L} p$-aminosalicylic acid at $\mathrm{pH} 11$ and a reaction time of 10 minutes
Compared to the previous research, AgNPs with $p$-aminosalicylic acid as stabilizing agent has lower stability than AgNPs with $p$-hydroxybenzoic acid as stabilizing agent whose SPR absorbance changes only as much as $1 \%$ from initial absorbance after 16 weeks ${ }^{16}$. The addition of amino group on the $p$-aminosalicylic acid maintains the reduction process and the AgNPs become smaller in size but less stable."

Furthermore, the comparison also made for 2,4-dihydroxybenzoic acid which was also has 3 functional groups, one carboxylic and two hydroxyphenolic groups. AgNPs synthesized by p-aminosalicylic has better stabilizing performance shown by the smaller SPR absorbance change than AgNPs synthesized by 2,4-dihydroxybenzoic acid whose SPR absorbance change as much as $8 \%$ after 6 weeks of storage. It was predicted that amino group has better reducing and stabilizing performance than hydroxyl group because the resulted AgNPs are smaller and more stable.

\section{The Mechanism of Silver Ion Reduction and AgNPs stabilization by p-Aminosalicylic Acid}

The proposed mechanism of silver ion reduction by $p$-aminosalicylic acid in AgNPs synthesis can be seen in Fig. 10. The reduction of silver ion by $p$-aminosalicylic acid was conducted under basic condition. Beside influences $p$-aminosalicylic acid, basic condition also influence the silver ion. In basic condition, the $\mathrm{H}$ atom from hydroxyl and amino moieties of $p$-aminosalicylic acid was deprotonated

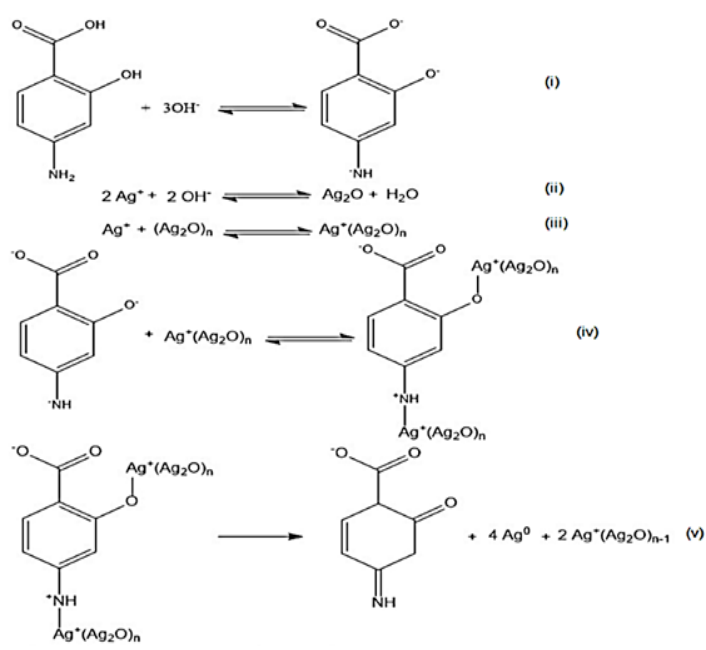

Fig. 10. The Reduction Mechanism of Silver lon by p-Aminosalicylic Acid 
(reaction i) and the moieties becomes more negative which enable it to react with the positive silver ion, while silver ion will aggregate to become $\mathrm{Ag}_{2} \mathrm{O}$ (reaction ii). In the water, the surface of $\mathrm{Ag}_{2} \mathrm{O}$ aggregates interacts with water and be hydrated to become $\mathrm{AgOH}$ which can absorb $\mathrm{Ag}^{+}$ion (reaction iii) ${ }^{23}$. The positive silver ion which surrounds the $\mathrm{Ag}_{2} \mathrm{O}$ aggregates then interacts with the deprotonated hydroxyl and amino moieties of $p$-aminosalicylic acid (reaction iv). Thus, the oxidation-reduction takes place with the $\mathrm{Ag}^{+}$ion as the center of the reaction. The $\mathrm{Ag}^{+}$ion was then reduced to become $\mathrm{Ag}^{0}$ particle which further becomes silver nanoparticles, and the deprotonated hydroxyl and amino moieties of $p$-aminosalicylic acid was oxidized to become keton and imine (reaction v). However, even if in the FTIR spectra of AgNPs there is absorption peak in the wavelength of $1635 \mathrm{~cm}^{-1}$, it cannot verify the keton and imine formation because this absorption can also come from carboxylic moiety.

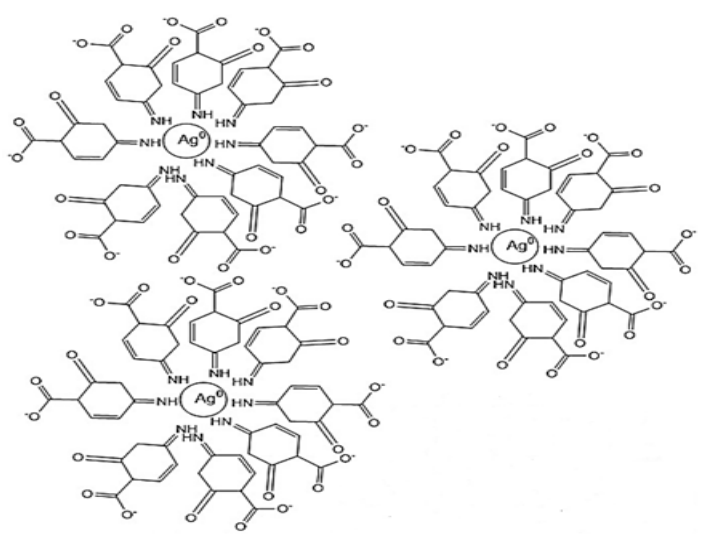

Fig. 11. The stabilization mechanism of AgNPs by p-aminosalicylic acid

Not only as the reducing agent of the $\mathrm{Ag}^{+}$ into AgNPs, p-aminosalicylic acid also stabilizes the formed AgNPs. The mechanism of AgNPs stabilization by $p$-aminosalicylic acid went through the repulsion force between adjacent deprotonated carboxylic acid moiety (Fig. 11). This mechanism was supported by the negative zeta potential value of the synthesized AgNPs. However, further analysis was needed to confirm these proposed mechanisms. The same mechanism was also proposed by previous studies ${ }^{16,17,18}$.

\section{CONCLUSION}

This present study reports the rapid synthesis of AgNPs from silver nitrate precursor solution with $p$-aminosalicylic acid as reducing and stabilizing agents. The synthesis process highly depends on the $\mathrm{pH}$, reaction time, and mole ratios of the reactants. The optimum synthesis condition was reached at $\mathrm{pH} 11$, reaction time of $10 \mathrm{~min}$ and a reactant mole ratio of 1:27 $\left(\mathrm{AgNO}_{3}\right.$ to $p$-aminosalicylic acid). The formed AgNPs had been characterized by Spectrophotometry UV-Vis, TEM, PSA, XRD, and FTIR. The particle shapes of the resulting nanoparticles are spherical with a size of $32 \mathrm{~nm}$. The mechanism of silver ion reduction and formed AgNPs stabilization by $p$-aminosalicylic acid were proposed.

\section{ACKNOWLEDGMENT}

The authors expressed special thanks to Ministry of Research and Higher Education of Indonesian Republic which has partly supported this research activities through Universitas Gadjah Mada, Yogyakarta, in the form of Penelitian Unggulan Perguruan Tinggi Grant and by providing scholarship of Master Education Program Leading to Doctoral Degree for Excellent Graduates (PMDSU) to the first author with contract number of 1984/UN1.P.III/ DIT-LIT/LT/2017.

\section{Conflict of Interest Statement}

All of the authors have read and agreed to this manuscript. The authors declare that there is no potential conflict of interest in this research.

\section{REFERENCES}

1. Fabrega, J.; Luoma, S. N.; Tyler, C. R.; Galloway, T. S.; Lead, J. R. Environ. Int., 2011, 37, 517-531.

2. Rodríguez-Argüelles, M. C.; Sieiro, C.; Cao, R.; Nasi, L. J. Colloid Interface Sci., 2011, 364, 80-84.
3. Prabhu, S.; Poulose, E. K. Int. Nano Lett., 2012, 32, 1-10.

4. Fouda, M. M.; El-Aassar, M.; Al-Deyab, S. S. Carbohydr. Polym., 2013, 92, 1012-1017.

5. Tran, Q. H.; Nguyen, V. Q.; Le, A. T. Adv. Nat. Sci. Nanosci. Nanotechnol., 2013, 4, 1-20. 
6. Pandey, S.; Goswami, G. K.; Nanda, K. K. Int. J. Biol. Macromol., 2012, 51, 583-589.

7. Kang, C. Y.; Xi, D. L.; Chen, Y. Y.; Jiang, Z. L. Talanta., 2008, 74, 867-870.

8. Dubas, S.; T Pimpan, V. Mater. Lett., 2008, 62, 2661-2663.

9. Ratnarathorn, N.; Chailapakul, O.; Henry, C. S.; Dungchai, W. Talanta., 2012, 99, 552-557.

10. Balakumar, V.; Prakash, P.; Muthupandi, K.; Rajan, A. Sensors Actuators, B Chem., 2017, 241, 814-820.

11. Lu, Y.; Chou, K. J. Chinese Inst. Chem. Eng., 2008, 39, 673-678.

12. Bin Ahmad, M.; Lim, J. J.; Shameli, K.; Ibrahim, N. A.; Tay, M. Y. Molecules., 2011, 16, 7237-7248.

13. Huang, L.; Zhai, M. L.; Long, D. W.; Peng, J.; Xu, L.; Wu, G. Z.; Li, J. Q.; Wei, G. S. J. Nanoparticle Res., 2008, 10, 1193-1202.

14. Laudenslager, M.J.; Schiffman, J.D.; Schauer, C. L. Biomacromolecules., 2008, 9, 2682-2685.

15. Hassabo, A. G.; Nada, A. A.; Ibrahim, H. M.; Abou-Zeid, N. Y. Carbohydr. Polym., 2015, 122, 343-350.

16. Gusrizal, G.; Santosa, S. J.; Kunarti, E. S.;
Rusdiarso, B. Int. J. ChemTech Res., 2016, 9, 472-482.

17. Gusrizal, G.; Santosa, S.J.; Kunarti, E.S.;Rusdiarso, B. Asian J. Chem., 2017, 29, 1417-1422.

18. Susanthy, D.; Fadliah;Wahyuni, E. T.; Santosa, S. J. Mater. Sci. Forum., 2017, 901, 26-31.

19. Roto, R.; Marcelina, M.; Aprilita, N. H.; Mudasir, M.; Natsir, T. A.; Mellisani, B. Indones. J. Chem., 2017, 17, 439-445.

20. Liang, A.; Liu, Q.; Wen, G.; Jiang, Z. Trac-Trend Anal. Chem., 2012, 37, 32-47.

21. Susanthy, D.; Santosa, S. J.; Kunarti, E. S. Indones. J. Chem., 2018, 18, 421-427.

22. Patil, R. S.; Kokate, M. R.; Jambhale, C. L.; Pawar, S. M.; Han, S. H.; Kolekar, S. S. Adv. Nat. Sci. Nanosci. Nanotechnol., 2012, 3, 1-7.

23. Litvin, V. A.; Galagan, R. L.; Minaev, B. F. Colloids Surfaces A., 2012, 414, 234-243.

24. Gibson, N.; Shenderova, O.; Luo, T. J. M.; Moseenkov, S.; Bondar, V.; Puzyr, A.; Purtov, K.; Fitzgerald, Z.; Brenner, D. W. Diam. Relat. Mater., 2009, 18, 620-626.

25. Bin Ahmad, M.; Tay, M. Y.; Shameli, K.; Hussein, M. Z.; Lim, J. J. Int. J. Mol. Sci., 2011, 12, 4872-4884. 